\title{
Should off-pump coronary artery bypass surgery be abandoned: A potential solution
}

\author{
Harold L. Lazar, MD
}

See related article on pages $1820-9$ in the November 2014 issue.

In their meta-analysis, based on 22 studies enrolling more than 100,000 patients, Takagi and colleagues ${ }^{1}$ concluded that off-pump coronary artery bypass (OPCAB) graft surgery is associated with worse long-term ( $>5$ years) survival compared with on-pump coronary artery bypass (ONCAB) graft surgery. The number of grafts performed per patient and the index of completeness of revascularization was significantly greater in ONCAB versus OPCAB patients. Furthermore, the need for repeat revascularization, the incidence of recurrent angina, and rehospitalization for cardiacrelated issues were also more frequent in the OPCAB group.

Previous studies have shown a $37 \%$ reduction in late mortality in patients undergoing coronary artery bypass graft (CABG) who have undergone a complete versus an incomplete revascularization. ${ }^{2}$ Several studies have reported a higher incidence of incomplete revascularization with OPCAB techniques and this has been proposed as a mechanism for the decreased long-term survival in these patients. $^{2-7}$ OPCAB has also been associated with decreased graft patency, which may also be responsible for decreased long-term survival and an increased need for revascularization procedures. ${ }^{8}$ The results of the study by Tagaki and colleagues ${ }^{1}$ are similar to a recent Cochrane pooled analysis of data from more than 80 trials of ONCAB versus $\mathrm{OPCAB}$ patients, which shows superior short- and mid-term survival with the ONCAB technique.

Proponents of OPCAB have argued that OPCAB surgeons perform fewer grafts because they are asked to perform $\mathrm{OPCAB}$ on patients with primarily single- or double-vessel disease. However, in their study, Tagaki and colleagues ${ }^{1}$ control for this variable by including those studies in which an index of completeness of revascularization was reported. Proponents of OPCAB have also suggested that data from earlier studies did not use modern stabilizers, heart positioning devices, or intracoronary shunts, and that the experience of the surgeons was

\footnotetext{
From the Division of Cardiac Surgery, Boston Medical Center, Boston, Mass. Disclosures: Author has nothing to disclose with regard to commercial support. Received for publication Oct 2, 2014; accepted for publication Oct 2, 2014.

Address for reprints: Harold L. Lazar, MD, Division of Cardiac Surgery, Boston

Medical Center, 88 East Newton St, Boston, MA 02118 (E-mail: harold.lazar@ bmc.org).

J Thorac Cardiovasc Surg 2014;148:2475-6

0022-5223/\$36.00

Copyright (c) 2014 by The American Association for Thoracic Surgery

http://dx.doi.org/10.1016/j.jtcvs.2014.10.006
}

inadequate. However, in 2 recent large randomized trials involving OPCAB surgeons who had at least 2 years' experience and who had performed at least 100 procedures, there was no difference in death, mortality, or major adverse cardiac events (MACE) between OPCAB and ONCAB techniques. ${ }^{10,11}$ Similarly, in the German Off-Pump Coronary Artery Bypass Grafting in Elderly Patients Study, which involved experienced $\mathrm{OPCAB}$ surgeons performing surgery on patients age 75 years or older, there was no difference in mortality or MACE between OPCAB and ONCAB techniques. ${ }^{12}$ However, additional revascularization procedures within 30 days were more frequent in OPCAB patients and they also received fewer grafts. The increased need for early revascularization and the decreased graft/patient index in the OPCAB group raised concerns that this could lead to an increased incidence of MACE in these elderly patients.

The results of these trials may be responsible for the decline in the use of OPCAB procedures in the United States, which peaked at $23 \%$ in 2002 and declined to $17 \%$ in 2012. ${ }^{13}$ Furthermore, the decline in OPCAB seems to be driven by a decrease in high-volume centers by highvolume surgeons; a group that has been the principle advocate of this technique.

In view of these negative studies, should OPCAB surgery be abandoned $?^{14}$ In the hands of surgeons who are experts in OPCAB and have enthusiastically adopted this technique, there seems to be no difference in outcomes compared with ONCAB surgery. ${ }^{15}$ In fact, throughout Asia and particularly in India, most CABG surgery is performed off pump. Furthermore, there are younger surgeons who may wish to learn these techniques. OPCAB may also play a role in patients with a heavily diseased ascending aorta.

Clearly, all evidence suggests that OPCAB is not superior to ONCAB. Therefore, surgeons who perform OPCAB must demonstrate that they can achieve short- and longterm outcomes comparable with ONCAB, which is the gold standard for coronary surgical revascularization. In order to accomplish this, guidelines should be established for performing $\mathrm{OPCAB}$ surgery and an $\mathrm{OPCAB}$ registry must be maintained to ensure that outcomes comparable with ONCAB are achieved by individual surgeons. This is no different from any other new surgical procedure that differs from established gold standard surgical techniques such as transcatheter aortic valve replacement or specialized procedures such as mechanical assist devices where guidelines and registries are already established to ensure that properly trained surgeons perform the proper procedures to achieve the optimal outcomes. 
I would propose that the major cardiac surgical societies develop guidelines for the practice of OPCAB and establish criteria for surgeon training, patient selection, institutional requirements, standardization of operative techniques, and postoperative management. Surgeons would be required to perform $100 \mathrm{OPCAB}$ procedures over a 2-year period and be mentored by an expert OPCAB surgeon who has had at least 2 years of experience with this technique. Patients should be carefully selected. Only those patients in whom a complete revascularization can be performed should undergo OPCAB procedures. In those cases where the coronary anatomy is unattractive (diffuse small-vessel disease), in whom cardiomegaly may limit exposure and result in hemodynamic instability, or in whom other issues (chronic obstructive pulmonary disease, reoperation, presence of pericarditis) limit exposure of coronary vessels, OPCAB should not be attempted. It is well documented that converting from $\mathrm{OPCAB}$ to $\mathrm{ONCAB}$ on an emergency basis is associated with increased morbidity and mortality, whereas doing so an elective basis is not, therefore it is imperative that criteria be established in the guidelines for the safe conversion of OPCAB to ONCAB surgery. ${ }^{16,17}$ This would include more frequent use of elective intra-aortic balloon pumps, and determining from previous studies which patients are more apt to require conversion to $\mathrm{ONCAB}$ in order to avoid hemodynamic collapse. Institutions in which OPCAB is performed should provide teams of health care professionals who are consistently involved in these procedures, including dedicated anesthesiologists who are adept at handling the hemodynamic variability associated with this technique, nursing personnel who are familiar the various equipment required for this surgery, and adequate perfusion standby. Equipment must be made available to properly perform these techniques, including sternal retractors with platforms for stabilizers, coronary artery shunts, anastomotic connectors, and $\mathrm{CO}_{2}$ blowers. Protocols should be available for dealing with the degree of anticoagulation during the procedure and its reversal afterwards, methods to regulate the patient's temperature, and for the administration of antiplatelet agents after the procedure. A catheterization laboratory should be available if emergency angiography or percutaneous intervention is necessary.

Registries should be established to monitor both the early (30-day) and long-term (5 years) outcomes for all planned OPCAB procedures. This would include not only mortality but important MACE events such as myocardial infarctions, graft occlusions, recurrent angina, need for any repeat revascularization, and rehospitalization for acute coronary syndromes. This information would be available to the public and referring physicians as is now the case with CABG registries in several states (New York, Massachusetts). Unplanned OPCAB procedures such as those for unexpectedly severe ascending aortic disease would be excluded.
The goal of all surgical revascularization procedures is to perform a technical procedure with minimal morbidity and mortality, enhanced long-term survival, and maximal freedom from recurrent angina, acute coronary syndromes, and the need for further revascularization procedures. ONCAB continues to be the gold standard to achieve these goals. Developing guidelines and registries for OPCAB surgery will ensure that those surgeons who perform alternative $\mathrm{CABG}$ techniques continue to meet those goals.

\section{References}

1. Takagi H, Umemoto $\mathrm{T}$; for the ALICE Group. Worse long-term survival following off-pump than on-pump coronary artery bypass grafting. $J$ Thorac Cardiovasc Surg. 2014;148:1820-9.

2. Takagi H, Watanabe T, Mizuno Y, Kawai N, Umemoto T; for the ALICE Group. A meta-analysis of adjusted risk estimates for survival from observational studies of complete vs. incomplete revascularization in patients with multivessel disease undergoing coronary artery bypass grafting. Interact Cardiovasc Thorac Surg. February 13, 2014 [E-pub ahead of print].

3. Shroyer AL, Grover FL, Hattler B, Collins JF, McDonald GO, Kozora E, et al. A Veterans Affairs Randomized On/Off Bypass (ROOBY) Study Group. On-pump vs. off-pump coronary artery bypass surgery. $N$ Engl J Med. 2009; 361:1827-37.

4. Jarral OA, Saso A, Athanasiou T. Off-pump coronary artery bypass in patients with left ventricular dysfunction: a meta-analysis. Ann Thorac Surg. 2011;92: 1686-94.

5. Wijeysundera VN, Beattie WS, Djaiani G, Rao V, Borger MA, Karkouti K, et al. Off-pump coronary artery surgery for reducing mortality and morbidity; a metaanalysis of randomized and observational studies. J Am Coll Cardiol. 2005;46: 872-82.

6. Synnergren MJ, Ekroth R, Oden A, Rexius H, Wiklund L. Incomplete revascularization reduces survival benefit of coronary artery bypass grafting: Role of off-pump surgery. J Thorac Cardiovasc Surg. 2008;136:29-36.

7. Caputo M, Reeves BC, Rajkaruna C, Awair H, Angelini GV. Incomplete revascularization during OPCAB surgery is associated with reduced mid-term event-free survival. Ann Thorac Surg. 2005;80:2141-7.

8. Lim E, Drain A, Davies W, Edmonds L, Rosengard BR. A systematic review of randomized trials comparing revascularization rate and graft patency of off-pump and conventional coronary surgery. J Thorac Cardiovasc Surg. 2006;132:1409-13.

9. Moller CH, Penninga L, Wettersleu J, Steinbruchel VL, Gloud C. Off-pump vs. on-pump coronary artery bypass grafting for ischemic heart disease. Cochrane Database Syst Rev. 2012;CD007224.

10. Lamy A, Devereau PJ, Prabhakaran D, Taggart DP, Hu S, Paolasso E, et al. Offpump or on-pump coronary artery bypass grafting at 30 days. $N$ Engl J Med. 2012;366:1489-97.

11. Lamy A, Devereau PJ, Prabhakaran D, Taggart DP, Hu S, Paolasso E, et al. Effects of off-pump and on-pump coronary artery bypass grafting at one year. N Engl J Med. 2013;368:1179-88.

12. Diegeler A, Borgermann J, Kappert U, Brever M, Boning A, Ursulescu A, et al. Off-pump vs. on-pump coronary artery bypass grafting in elderly patients. $N$ Engl J Med. 2013;368:1189-98.

13. Bakaeem FG, Shroyer LW, Gammie JS, Sabik JF, Cornwell LD, Coselli JS, et al. Trends and use of off-pump coronary artery bypass grafting: results from the Society of Thoracic Surgeons adult cardiac surgery database. J Thorac Cardiovasc Surg. 2014;148:856-64.

14. Lazar HL. Should off-pump coronary artery bypass grafting be abandoned? Circulation. 2013;128:406-13.

15. Puskas JD, Williams WH, O’Donnell R, Patterson RE, Sigmund SR, Smith AS, et al. Off-pump and on-pump coronary artery bypass grafting are associated with similar graft patency, myocardial ischemia and freedom from reintervention: long-term follow-up of a randomized trial. Ann Thorac Surg. 2011;9:1836-43.

16. Edgarton JR, Dewy TM, Magee MJ, Herbert MA, Prince SL, Jones KK, et al. Conversion in off-pump coronary artery bypass grafting: analysis of predictors and outcomes. Ann Thorac Surg. 2013;76:1138-42.

17. Mukherjee D, Ahmed K, Baig K, Patel VM, Darzi A, Athanasiou T. Conversion and safety in off-pump coronary artery bypass: a system failure that needs reemphasis. Ann Thorac Surg. 2011;91:630-9. 